\title{
A social work study on investigating organizational relationship: A case study of sport organization
}

\author{
Khodayar Momeni $^{\mathrm{a}^{*}}$, Allahyar Arabmomeni ${ }^{\mathrm{b}}$, Mohammad Reza Iravanic and Gholamreza Tajbakhsh ${ }^{\mathrm{d}}$
}

${ }^{a}$ Islamic Azad University of Kerman, Science and Research, Kerman Branch, Iran

${ }^{b}$ Department of Human Science of Islamic Azad University Khomeinishahr Branch, Isfahan, Iran

${ }^{c}$ Department of Social Work, Islamic Azad University of Khomeinishahr, Khomeinishahr Branch, Daneshjou Blvd, Iran

${ }^{d}$ Assistant Professor of Sociology Grand Ayatollah Boroujerd, Iran

A R T I C L E I N F O AB S T R C T

Article history:

Received July 16, 2012

Received in Revised form

August, 27, 2012

Accepted 20 September 2012

Available online

September 282012

Keywords:

Sport

Organizational relationships

Cooperation
Organizational relationship plays an important role in developing more cooperation among members of employees. Today, there is no doubt that people are mostly considered as the primary source of creating value added activities. Therefore, it is important to learn more about organizational relationship in different organizations and detect possible barriers on developing such relationships. In this paper, we present an empirical study to detect the status of organizational relationship in Sport organization of province of Esfahan, Iran. The proposed study designs a questionnaire consists of five parts including informative, freedom, one-side relationship, formality and openness. All questions were designed in Likert scale from one to five and Cronbach alpha was calculated as 0.94 . The results of the study shows organizational relationship is in good position in average and all different cities of Iran.

\section{Introduction}

Organizational relationship plays an important role in developing more cooperation among members of employees. Organizational relationships such as formal or informal could help increase communications and help organizations build better working environment. There are also different hierarchal relationships among relationships such as horizontal or vertical. Jaspers and van den Ende (2006) argued that the organizational form of a buying firm's vertical relationship with a supplier could be described as a configuration of four distinct. Ni (2006) investigated the relationships as organizational resources by investigating public relationships effect through its connection with organizational strategies.

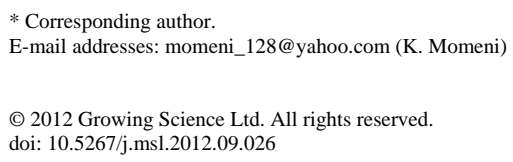


Perks and Vaux Halliday (2003) investigated the evolution of trust in long-term inter-organizational relationships. It started with a conceptualization of the nature of trust in various forms of interorganizational relationships. They reported that accelerated trust development was frequently necessary to quickly transfer resources and achieve value from the relationship. The findings demonstrated how diverse and dynamic trust signaling mechanisms played a critical role in the evolutionary trust creation process.

Jafari and Bidarian (2012) in another work investigated the relationship between organizational justice and organizational citizenship behavior. Celep and Eler Yilmazturk (2012) in another work studied the relationship among organizational trust, multidimensional organizational commitment and perceived organizational support in educational organizations. According to their survey, there was a meaningful and positive correlation between teachers' perceived organizational support and their organizational commitment.

Lamin and Dunlap (2011) investigated how access to some knowledge available to firms via organizational relationships could improve learning opportunities, which are necessary for the development of complex technological requirements. They used a sample of 852 information of emerging economy business units from the Indian software industry over the period of 1992-2000 and reported that developing strong domestic intra-organizational relationships, through affiliation with a relatively diversified business group, could facilitate complex technological capabilities. For the case of foreign inter-organizational relationships, they reported that bigger foreign client contact could enhance the complexity of firm technological capabilities.

Nevertheless, achieving knowledge from domestic inter-organizational relationships seemed to hinder the development of firm complex technological capabilities. They also reported that having greater access to knowledge from foreign intra-organizational relationships, embedded within foreign subsidiaries, could not necessarily lead to the development of complex firm technological capabilities. They concluded that for emerging economy firms wishing to improve their complex technological capabilities, there could be diminishing advantage on learning from and acquiring knowledge available within specific kinds of formal organizational relationships.

Choe (2008) developed a model, which determines different types of inter-organizational relationships and groups them into two broad types: transactional and managerial. Choe (2008) also investigated the impacts of inter-organizational information systems (IOS) and traditional communication media (TCM) on the exchanged information using a regression analysis. The results of stepwise regression demonstrated that the use of value chains was the most substantial factor impacting the exchange of both kinds of data.

In examining the effect of the information exchanged to increase production performance, it appeared that various types of data affected different aspects. Based on the usage level of the media and the different kinds of information exchanged, Choe (2008) defined four categories of inter-organizational relationships and their particular characteristics including traditional links for coordination, electronic links for coordination, strategic alliances, and virtual organizations.

Weck and Blomqvist (2008) investigated the effect of inter-organizational relationships in the development of patents in a knowledge-based approach. They examined the impact of different interorganizational relationships in patent development and competitiveness. They used a case study of a 
European telecom operator and reported that interaction with R\&D consortia, suppliers and customers are necessary to support development of new ideas for patents and in solving associated problems.

Jekanyika Matanda and Freeman (2009) investigated the impacts of perceived environmental uncertainty on exporter-importer inter-organizational relationships and export performance improvement. They developed a technique, which criticized export market buyers gain advantage by leveraging internal resources using some data from 262 fresh-produce export suppliers in Zimbabwe. They studied the impact of perceived environmental uncertainty on inter-organizational relationships and supplier export efficiency and reported that perceived environmental uncertainty dimensions had different impacts over inter-organizational relationships. Their results backed the relational theory's tenet that commitment to future exchanges is related to export performance improvement.

Organizational relationship in a supply chain is another area of research where a good relationship among different partners helps them understand their needs. Ellis et al. (2012) investigated businessto-business (B2B) marketing values and knowledge systems in India and their effect on identity construction in industrial networks. The study merged a technique into more interpretive territory by acknowledging the processes of social construction in networks as articulated by the IMP Group. Neumann (2010) investigated the theory behind ex ante governance decisions in inter-organizational relationships and applied an explanatory case study involving an inter-firm relationship between two European airlines to evaluate the theoretical propositions. They reported that the more powerful of the two partners deliberately relinquished the benefits was related to its ex ante privileged position.

In this paper, we present an empirical study to learn more about the status of organizational relationship among employees of Sport organization of province of Esfahan, Iran. The organization of this paper first presents details of the proposed study in section 2, explain the findings in section 3 and concluding remarks are given in the last to summarize the contribution of the paper.

\section{The proposed study}

The proposed study of this paper investigates organizational relationship among employees of Esfahan sport organization. The sample size is chosen based on the following

$$
n=\frac{N \times z_{\alpha / 2}^{2} \times p \times q}{\varepsilon^{2} \times(N-1)+z_{\alpha / 2}^{2} \times p \times q},
$$

where $N$ is the population size, $p=1-q$ represents the yes/no categories, $z_{\alpha / 2}$ is CDF of normal distribution and finally $\varepsilon$ is the error term. Since we have $p=0.5, z_{\alpha / 2}=1.96$ and $N=205$, the number of sample size is calculated as $n=132$. The proposed study designed a questionnaire and distributed first among some experts to verify the content.

The questionnaire consists of five main categories including informative, freedom, one-side relationship, formality and openness. All questions were designed in Likert scale from one to five. Cronbach alpha was calculated as 0.94 and this is well above the minimum requirement. Fig. 1 shows details of the resonances for organizational relationships. 


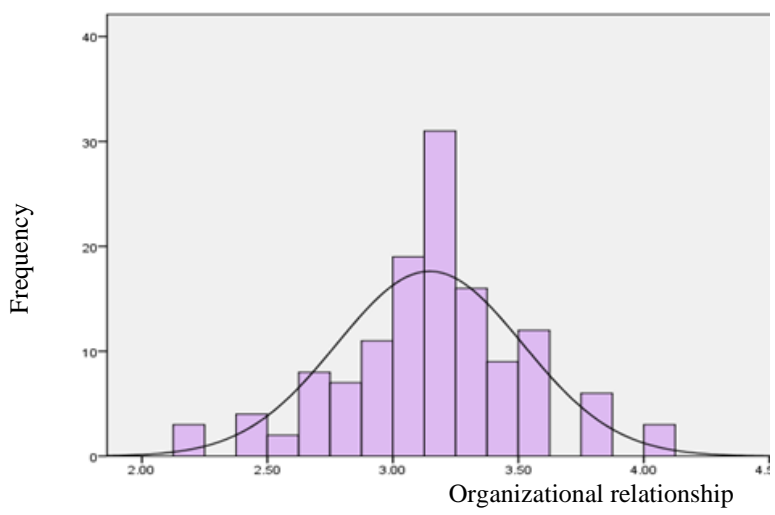

Fig. 1. Organizational relationship

\subsection{Personal characteristics of the participants}

In our survey, $59 \%$ of the participants were male and $41 \%$ were female and in terms of their marital status, $79 \%$ of the participants were married and the remaining $21 \%$ were single. In terms of educational background, the people who participated in our survey were mostly educated. In fact, $63 \%$ of the participants hold bachelor degrees of science and $51 \%$ of the participants did their education in the area of sport science.

\section{The results}

In this section, we present details of our findings on organizational relationships. The average score is 2.15 and the maximum score is 4.10 with $3.14 \pm 0.13$. Fig. 2 shows details of our findings.

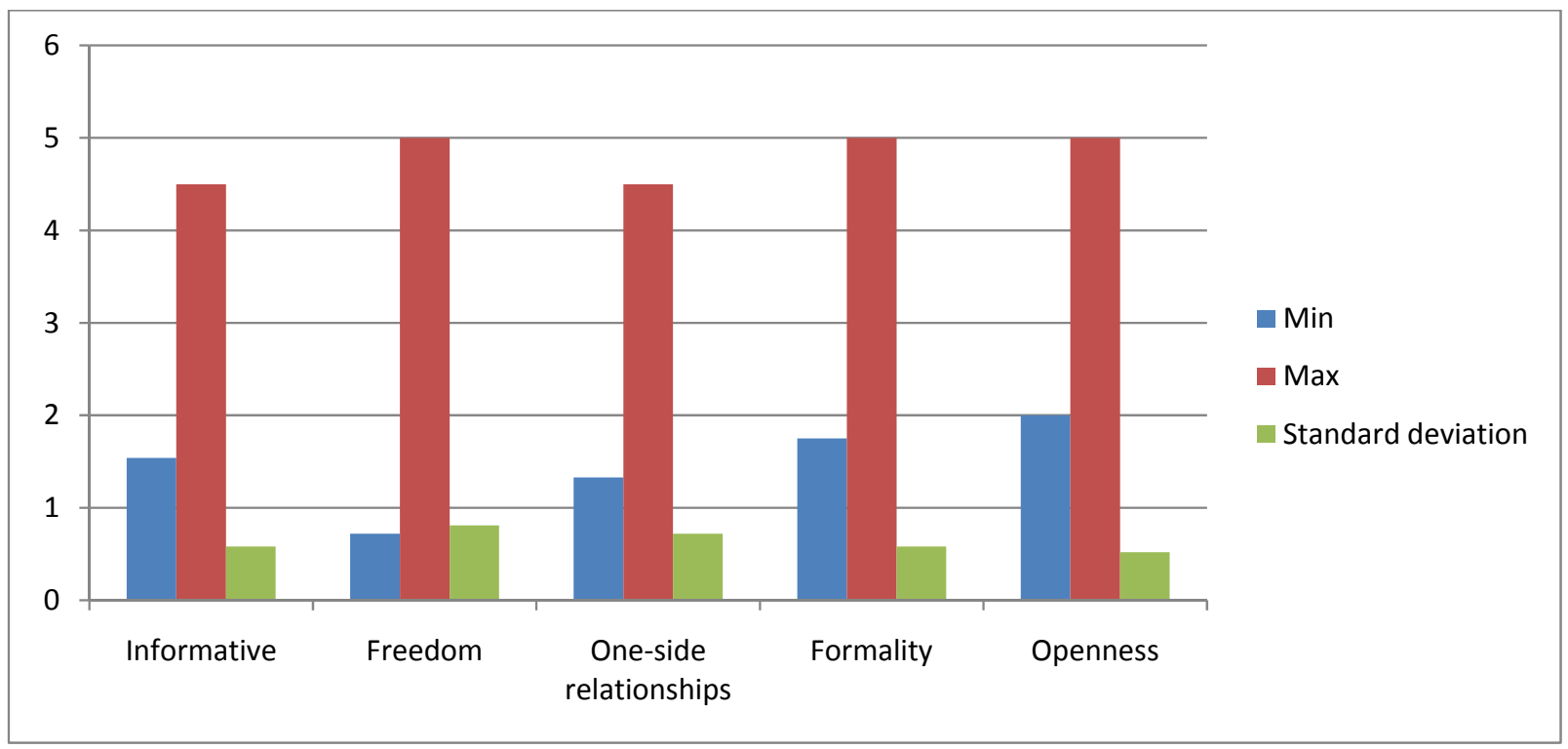

Fig. 2. Min, max and standard deviation of organization relationships

As we can observe from Fig. 2, openness maintains the highest value with minimum standard deviation compared with other components, followed by formality and freedom. Informative and oneside relationships appear as the last priority according to our survey. The study was also accomplished in different cities of province of Esfahan and Fig. 3 shows mean and standard deviation of all organizational relationship. 


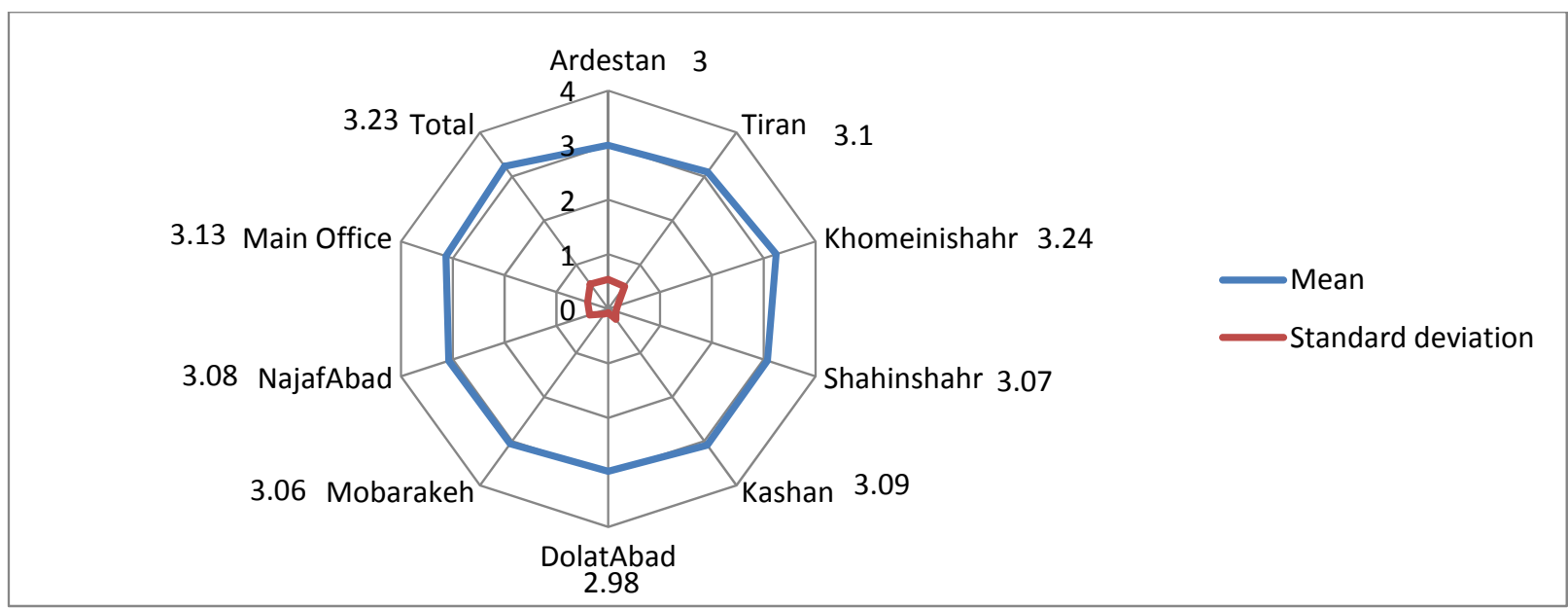

Fig. 3. The mean and standard deviation of organizational relationship in different cities

As we can observe, the mean of organizational relationship in different cities are almost above the desirable level of 3 out of 5 Likert components. Khomeinishahr is the city with the highest rank and DolatAbad maintained the lowest mean value.

\section{Conclusion}

In this paper, we have presented an empirical study to measure organizational relationship in a sport organization located in province of Esfahan, Iran. The proposed study of this paper designed a questionnaire in five different categories including informative, freedom, one-side relationship, formality and openness. The study was accomplished in nine different cities located in province of Esfahan and we have measured the relative weights of all components. The results of the study indicates that organizational relationship in all cities were in good position and improving such skills could help them contribute more in this organization.

\section{Acknowledgement}

The authors would like to thank the officials of Sport organization for cordially supporting accomplishment of this survey. We are also delighted from the comments received from anonymous referees on earlier version of this paper.

\section{References}

Celep, C., \& Eler Yilmazturk, O. (2012). The relationship among organizational trust, multidimensional organizational commitment and perceived organizational support in educational organizations. Procedia - Social and Behavioral Sciences, 46, 5763-5776.

Choe, J.M.(2008). Inter-organizational relationships and the flow of information through value chains. Information \& Management, 45(7), 444-450.

Ellis, N., Rod, M., Beal, T., \& Lindsay, V. (2012). Constructing identities in Indian networks: Discourses of marketing management in inter-organizational relationships. Industrial Marketing Management, 41(3), 402-412.

Jafari, P., \& Bidarian, S. (2012). The relationship between organizational justice and organizational citizenship behavior. Procedia - Social and Behavioral Sciences, 47, 1815-1820

Jaspers, F., \& van den Ende, J. (2006). The organizational form of vertical relationships: Dimensions of integration. Industrial Marketing Management, 35(7), 819-828. 
Jekanyika Matanda, M., \& Freeman, S. (2009). Effect of perceived environmental uncertainty on exporter-importer inter-organisational relationships and export performance improvement. International Business Review, 18(1), 89-107

Lamin, A., \& Dunlap, D. (2011). Complex technological capabilities in emerging economy firms: The role of organizational relationships. Journal of International Management, 17(3), 211-228.

Neumann, K. (2010). Ex ante governance decisions in inter-organizational relationships: A case study in the airline industry. Management Accounting Research, 21(4), 220-237.

Ni, L. (2006). Relationships as organizational resources: Examining public relations impact through its connection with organizational strategies. Public Relations Review, 32(3), 276-281.

Perks, H., \& Vaux Halliday, S. (2003). Sources, signs and signalling for fast trust creation in organisational relationships. European Management Journal, 21(3), 338-350

Weck, M., \& Blomqvist, K. (2008). The role of inter-organizational relationships in the development of patents: A knowledge-based approach. Research Policy, 37(8), 1329-1336. 